University of Nebraska - Lincoln

DigitalCommons@University of Nebraska - Lincoln

6-1-2004

\title{
Growth and magnetism of FePt:C composites in nanoscale channels
}

Yucheng Sui

University of Nebraska-Lincoln, ysui2@unl.edu

J. Zhou

University of Nebraska - Lincoln

Xingzhong Li

University of Nebraska-Lincoln, xli2@unl.edu

Ralph Skomski

University of Nebraska-Lincoln, rskomski2@unl.edu

David J. Sellmyer

University of Nebraska-Lincoln, dsellmyer@unl.edu

Follow this and additional works at: https://digitalcommons.unl.edu/physicssellmyer

Part of the Physics Commons

Sui, Yucheng; Zhou, J.; Li, Xingzhong; Skomski, Ralph; and Sellmyer, David J., "Growth and magnetism of FePt:C composites in nanoscale channels" (2004). David Sellmyer Publications. 23.

https://digitalcommons.unl.edu/physicssellmyer/23

This Article is brought to you for free and open access by the Research Papers in Physics and Astronomy at DigitalCommons@University of Nebraska - Lincoln. It has been accepted for inclusion in David Sellmyer Publications by an authorized administrator of DigitalCommons@University of Nebraska - Lincoln. 


\title{
Growth and magnetism of FePt:C composites in nanoscale channels
}

\author{
Y. C. Sui, ${ }^{\text {a) }}$ J. Zhou, X. Z. Li, R. Skomski, and D. J. Sellmyer \\ Department of Physics and Astronomy and Center for Materials Research and Analysis, \\ University of Nebraska, Lincoln, Nebraska 68588-0111
}

(Presented on 6 January 2004)

\begin{abstract}
Nanochannels of porous alumina films were used as nanoreactors for the reaction of hydrogen gas with a mixture of Fe nitrate and Pt chloride. This results in the formation of of FePt clusters within the nanochannels. Both the sizes of the clusters and the coercivity the cluster assembly increase with the increase of annealing temperature. In order to reduce excessive agglomeration at high temperature, carbon was introduced by chemical vapor deposition and FePt:C composites in nanoscale channels were created. When FePt clusters were synthesized with carbon and heat treated at high temperatures, cluster sizes were much smaller than those without carbon, suggesting that the introduced carbon serves effectively to block the agglomeration of clusters. The coercivity of the FePt:C composite containing the smaller clusters is as high as $29.0 \mathrm{kOe}$. (c) 2004 American Institute of Physics. [DOI: 10.1063/1.1688654]
\end{abstract}

\section{INTRODUCTION}

The high magnetization $\left(\sim 1100 \mathrm{emu} / \mathrm{cm}^{3}\right)$ and large anisotropy $\left(K_{u}>5 \times 10^{7} \mathrm{erg} / \mathrm{cm}^{3}\right)$ of $L 1_{0}$-ordered FePt clusters make their assembly very promising for both nanocomposite magnets and high-density magnetic recording media. ${ }^{1-3}$ It is normally found that the coercivities of the FePt clusters increase when they are treated at high temperatures, which results from the high degree of chemical ordering and improved magnetocrystalline anisotropy. It is also found that aggregation of clusters occurs when they are treated at high temperature, which is not desired for nanocomposite magnets or magnetic recording media, and there is not a simple method to prevent them from aggregating. When carbon is used as a nonmagnetic matrix to isolate the FePt clusters, it is found that carbon restricts the growth of particles and delays the onset of atomic ordering with annealing. ${ }^{3,4}$ In this study, cluster-assembled FePt:C composites were produced within the nanochannels of alumina films by combining hydrogen reduction and chemical vapor deposition (CVD). ${ }^{2,5}$ The presence of carbon blocks the agglomeration of fine clusters when heated to high temperatures. The sizes and the morphologies of FePt clusters inside the nanochannels are studied together with their magnetic properties.

\section{EXPERIMENTAL METHOD}

The experiments can be roughly divided into four successive steps. The fabrication of porous alumina films with nanochannels passing through them is the first step. Electropolished pure aluminum foils were anodized in a $0.1 \mathrm{M}$ oxalic acid aqueous solution at $100 \mathrm{~V}$ for $10 \mathrm{~min}$. When the $\mathrm{Al}$ substrate was stripped in $\mathrm{HCl}$ aqueous solution, the barrier layer is exposed and etched away using a $0.3 \mathrm{M} \mathrm{H}_{3} \mathrm{PO}_{4}$ aqueous solution for $6 \mathrm{~h}$. Following this procedure, porous alumina films with thickness about $50 \mu \mathrm{m}$ and average pore

\footnotetext{
a) Author to whom correspondence should be addressed; electronic mail: ysui@unlserve.unl.edu
}

diameter about $200 \mathrm{~nm}$ were obtained. In the second step, a $0.8 \mathrm{M}$ alcohol solution of a $\mathrm{Fe}\left(\mathrm{NO}_{3}\right)_{3} \cdot 9 \mathrm{H}_{2} \mathrm{O}$ and $\mathrm{H}_{2} \mathrm{PtCl}_{6}$ - $6 \mathrm{H}_{2} \mathrm{O}$ mixture with $\mathrm{Fe}: \mathrm{Pt}$ atomic ratio of $1: 1$ was prepared and loaded into the pores by a pressure cell. The impregnated films were dried in vacuum for $30 \mathrm{~min}$ and transferred into a tubular quartz furnace for hydrogen reduction at $650{ }^{\circ} \mathrm{C}$ for $1 \mathrm{~h}$.

Third, the flowing hydrogen was switched to high-purity nitrogen containing $3 \mathrm{vol} \% \mathrm{C}_{2} \mathrm{H}_{2}$ at the same temperature for 30 min for preparing FePt:C nanocomposites. ${ }^{6}$ The $\mathrm{C}_{2} \mathrm{H}_{2}$ component was stopped at the end of the CVD while the flow of $\mathrm{N}_{2}$ was retained. The oven temperature was increased to the programmed high temperature after CVD and kept constant for another $30 \mathrm{~min}$ in high-purity $\mathrm{N}_{2}$, and then cooled to room temperature. For comparison, additional sets of FePt samples without carbon were annealed at high temperatures in hydrogen. Carbon was introduced similarly after high-temperature treatment for the purpose of facilitating the comparison of particle sizes and morphologies. Finally, a HF aqueous solution was used to dissolve the alumina matrix, and the FePt:C nanocomposites were released, cleaned, and dispersed into acetone. One drop of the suspension of the black precipitates on a transmission electron microscopy (TEM) copper grid was used for morphology observation. $\mathrm{X}$-ray diffraction (XRD) analysis was carried out with $\mathrm{Cu}$ $K \alpha$ radiation. Magnetic properties were measured by a Quantum Design superconducting quantum interference device.

\section{RESULTS AND DISCUSSION}

\section{A. Formation of FePt $L 1_{0}$ clusters inside nanochannels}

When the alcohol solution of the $\mathrm{Fe}\left(\mathrm{NO}_{3}\right)_{3} \cdot 9 \mathrm{H}_{2} \mathrm{O}$ and $\mathrm{H}_{2} \mathrm{PtCl}_{6} \cdot 6 \mathrm{H}_{2} \mathrm{O}$ mixture with $\mathrm{Fe}: \mathrm{Pt}$ atomic ratio of $1: 1$ was loaded into nanochannels of porous alumina film and reduced at different temperatures in flowing hydrogen, $L 1_{0}$-phase FePt clusters were formed. The corresponding XRD patterns are shown in Fig. 1. The coercivities of 


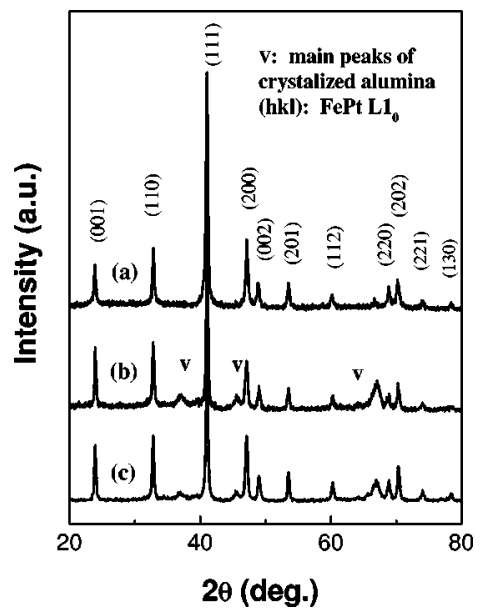

FIG. 1. XRD patterns of FePt clusters heated at different temperatures with and without carbon: (a) H-650 $\times 1 \mathrm{~h}+\mathrm{CVD}+\mathrm{N}-650 \times 30 \mathrm{~min}$; (b) $\mathrm{H}-650$ $\times 1.5 \mathrm{~h}+\mathrm{H}-900 \times 30 \mathrm{~min}+\mathrm{CVD}$; (c) $\mathrm{H}-650 \times 1 \mathrm{~h}+\mathrm{CVD}+\mathrm{N}-900 \times 30 \mathrm{~min}$. $\mathrm{H}-650 \times 1 \mathrm{~h}$ indicates heating in hydrogen at $650^{\circ} \mathrm{C}$ for $1 \mathrm{~h}$; N-650 $\times 30$ min indicates heating in high pure $\mathrm{N}_{2}$ at $650^{\circ} \mathrm{C}$ for $30 \mathrm{~min}$; CVD indicates carbon coating by chemical vapor deposition in a gas mixture of $\mathrm{N}_{2}$ and 3 vol $\% \mathrm{C}_{2} \mathrm{H}_{2}$ at $650{ }^{\circ} \mathrm{C}$ for $30 \mathrm{~min}$.

samples heated at different temperatures are given in Fig. 2. It is clear that the coercivity increases with increasing reaction temperature, and reaches a peak value of $27.3 \mathrm{kOe}$ at $900^{\circ} \mathrm{C}$, which is higher than the maximum value of $L 1_{0}$ phase CoPt clusters synthesized by hydrogen reduction of $\mathrm{Co}$ nitrate and $\mathrm{Pt}$ chloride mixture. ${ }^{2}$ The higher coercivity of $L 1_{0}$ phase FePt than CoPt comes mainly from the higher anisotropy field and the higher degree of its chemical order due to the higher annealing temperature.

In this study, the long channels inside the alumina films act as containers for storing the alcohol solution of the $\mathrm{Fe}$ and Pt salt mixture and the nanoreactors in which hydrogen reduction of Fe nitrate and $\mathrm{Pt}$ chloride takes place. Although the nanochannels are long (about $50 \mu \mathrm{m}$ ) with small diameter, the $\mathrm{Fe}$ nitrate and $\mathrm{Pt}$ chloride mixture within the pores was reduced completely, which indicates that hydrogen is a highly efficient reducing agent for $\mathrm{Fe}$ nitrate and Pt chloride at the nanometer scale. No detectable reaction between FePt

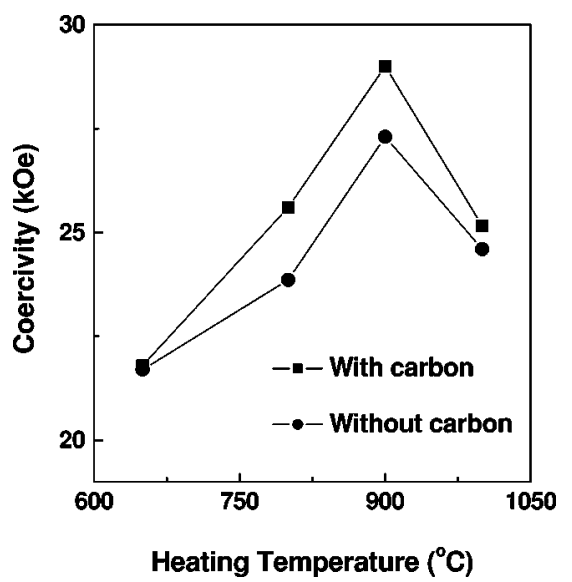

FIG. 2. The dependence of coercivities on annealing temperatures for FePt cluster assembly with and without carbon.

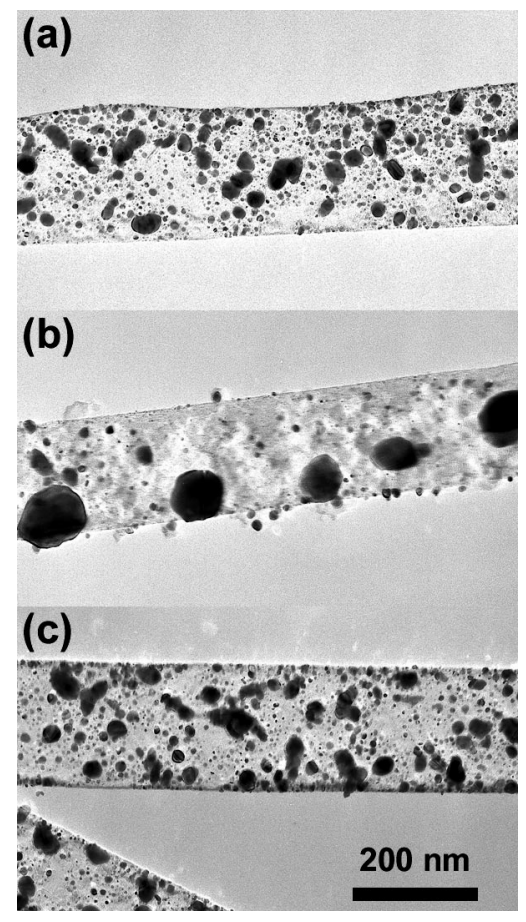

FIG. 3. TEM micrographs of FePt:C composite. (a), (b), and (c) were taken on the corresponding samples of a, b, and c as described in Fig. 1.

and alumina matrix is found after hydrogen reduction at 900 and $1000^{\circ} \mathrm{C}$, suggesting that the alumina matrix is a stable substrate for the preparation of FePt $L 1_{0}$ phase using hydrogen reduction.

\section{B. FePt:C composites produced by CVD}

When a $\mathrm{N}_{2}$ and $\mathrm{C}_{2} \mathrm{H}_{2}$ gas mixture was introduced into the quartz tubular oven at $650{ }^{\circ} \mathrm{C}$ after hydrogen reduction, the thermal pyrolysis of $\mathrm{C}_{2} \mathrm{H}_{2}$ inside the pores took place with the catalytic assistance from FePt clusters. Carbon atoms were released from $\mathrm{C}_{2} \mathrm{H}_{2}$ and deposited onto the clusters and the walls of pores in the alumina matrix, ${ }^{6,7}$ which leads to the formation of an FePt:C composite inside the pores. When the alumina matrix is removed by chemical etching, an FePt:C composite with a shape of nanofiber was released. The sizes, morphologies, and distribution of the FePt clusters along the pores were preserved, which can be examined conveniently using TEM. The CVD process is designed to introduce carbon barriers between the FePt clusters, in order to prevent the excessive growth of the FePt clusters when treated at high temperatures.

Figure 1(c) shows the XRD pattern of an FePt:C composite annealed at $900{ }^{\circ} \mathrm{C}$. Compared with the $\mathrm{FePt}$ samples annealed at the same temperature without carbon [Fig. 1(b)], no observable structural difference can be detected between the samples with or without carbon. This phenomenon also holds true for samples heated at $1000^{\circ} \mathrm{C}$. Additionally, no characteristic peaks can be indexed to carbon in both patterns, suggesting that the carbon formed inside the pores has such a fine structure that it cannot be detected by XRD.

Figure 3 shows the morphologies of the FePt:C composite released from porous templates. The mean cluster sizes were extracted using log-normal fitting of the histogram of 

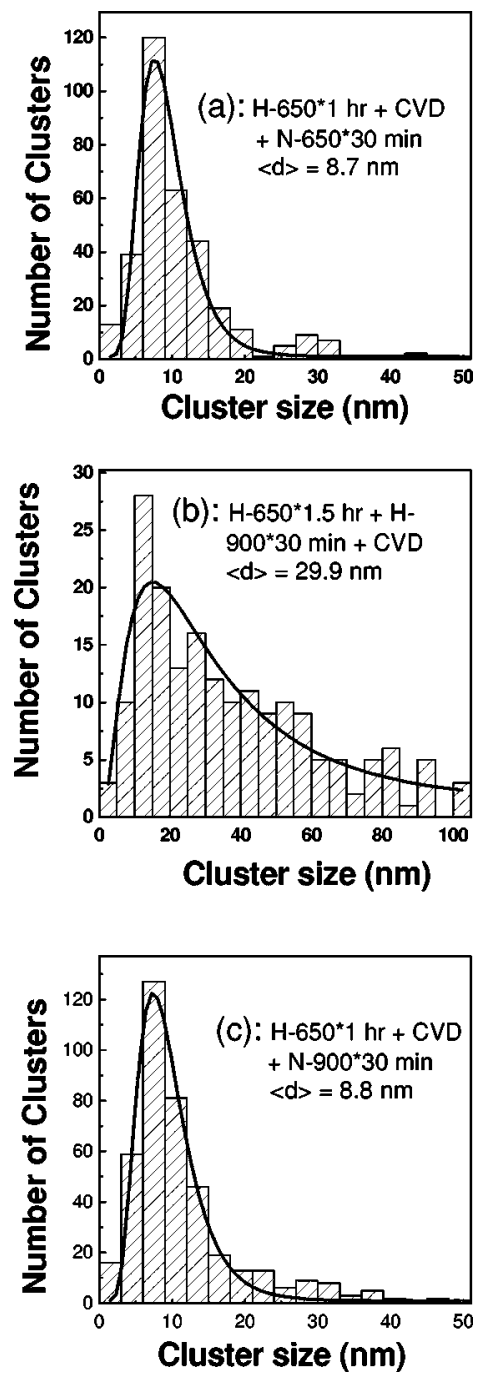

FIG. 4. Mean cluster size of sample a, b, and c (as described in Fig. 1) extracted from the corresponding histogram by log-normal fittings.

corresponding samples and shown in Fig. 4. When the impregnated porous alumina film was reduced in hydrogen at $650{ }^{\circ} \mathrm{C}$ for $1.5 \mathrm{~h}$ and embedded in carbon, the average $\mathrm{FePt}$ cluster size is $8.7 \mathrm{~nm}$, as shown in Figs. 3(a) and 4(a). When the clusters were heated at $900{ }^{\circ} \mathrm{C}$ without carbon, the mean size is $29.9 \mathrm{~nm}$ as shown in Figs. 3(b) and 4(b). It is clear that significant agglomeration of FePt clusters occurred when the samples are treated at high temperature. When the FePt:C composite was heated at $900^{\circ} \mathrm{C}$ for 30 min, as shown in Fig. $3(\mathrm{c})$, the FePt clusters have a similar size range as the lowtemperature treated ones [Fig. 3(a)] and the mean size is 8.8 $\mathrm{nm}$. This result indicates that the agglomeration of FePt clusters is effectively blocked by the introduction of carbon during heating at $900^{\circ} \mathrm{C}$. The average cluster size is $9.1 \mathrm{~nm}$ for FePt:C composite after heating at $1000^{\circ} \mathrm{C}$, which is not shown in this article. Thus the carbon works effectively in confining the growth of $\mathrm{FePt}$ particles even at $1000^{\circ} \mathrm{C}$ annealing. Assuming that the agglomeration of $\mathrm{FePt}$ clusters was induced by heat-driven surface $\mathrm{Fe}$ and $\mathrm{Pt}$ diffusion, the introduction of the carbon barrier will increase the activation energy for surface diffusion, which in turn reduces the diffusion rate drastically. When the temperature is very high, for example $1000^{\circ} \mathrm{C}$, the $\mathrm{Fe}$ and $\mathrm{Pt}$ diffusion may be activated through the carbon barrier or the interface between carbon and alumina matrix, so a slight increase of particle size is observed. Since the introduction of carbon prohibits the excessive agglomeration of FePt clusters and reduces the exchange interaction among clusters, the coercivities of FePt:C composites are higher than the FePt clusters without carbon when annealed at the same temperatures. The highest coercivity $(29.0 \mathrm{kOe})$ is reached for $\mathrm{FePt}: \mathrm{C}$ composite heated at $900{ }^{\circ} \mathrm{C}$ for $30 \mathrm{~min}$. Further increase of the heating temperature to $1000^{\circ} \mathrm{C}$ decreases the coercivity. This may be partly caused by incoherent rotation during magnetization reversal.

\section{SUMMARY}

Cluster-assembled FePt:C composites are synthesized within the nanopores of porous alumina films. The carbon between the particles serves as an effective barrier to reduce the surface diffusion of FePt and effectively prevents the agglomeration of particles when treated at high temperatures. A coercivity value of $29.0 \mathrm{kOe}$ is achieved for FePt:C nanocomposite heated at $900^{\circ} \mathrm{C}$. Due to the confinement and the isolation of the nanochannels in the templates, the resulting FePt:C composite has nanofiber-like morphology. The diameter of the nanochannels can be varied from $5 \mathrm{~nm}$ to several hundred nanometers. Different magnetic clusters can be introduced by the same experimental procedure described in this article. In this sense, quasione-dimensional composites of carbon with different magnetic clusters can be produced, which may find applications in magnetic nanotechnology.

\section{ACKNOWLEDGMENTS}

This work is supported by AFOSR, NSF-MRSEC, DOE, NRI, and CMRA. The authors would like to thank Steven Michalski for assistance.

${ }^{1}$ S. H. Sun, C. B. Murray, D. Weller, L. Folks, and A. Moser, Science 287, 1989 (2000)

${ }^{2}$ Y. Sui, L. Yue, R. Skomski, X. Z. Li, J. Zhou, and D. J. Sellmyer, J. Appl. Phys. 93, 7571 (2003).

${ }^{3}$ M. Yu, Y. Liu, A. Moser, D. Weller, and D. J. Sellmyer, Appl. Phys. Lett. 75, 3992 (1999)

${ }^{4}$ Y. Zhang, J. Wan, M. J. Bonder, G. C. Hadjipanayis, and D. Weller, J. Appl. Phys. 93, 7175 (2003).

${ }^{5}$ Y. C. Sui, B. Z. Cui, L. Martinez, R. Perez, and D. J. Sellmyer, Thin Solid Films 406, 64 (2002).

${ }^{6}$ Y. C. Sui, D. R. Acosta, J. A. González-León, A. Bermúdez, J. Feuchtwanger, B. Z. Cui, J. O. Flores, and J. M. Saniger, J. Phys. Chem. B 105, $1523(2001)$

${ }^{7}$ Y. C. Sui, B. Z. Cui, R. Guardian, D. R. Acosta, R. Perez, and L. Martinez, Carbon 40, 1011 (2002) 